\title{
A Study on Causative Psych Verbs and Their Definitions in the Learner's Chinese Dictionary
}

\author{
Lixin Xia \\ Center for Lexicographical Studies \\ Guangdong University of Foreign Studies \\ Guangzhou, China
}

\begin{abstract}
This paper studied the causative psych verbs and their treatment in the dictionaries for CFL (Chinese as a Foreign Language) learners by a comparative method, with an aim to improve their presentation in the dictionaries. First, it elaborated on the differences between Chinese and English in the semantic and syntactic features of the verbs. And then the definitions and representation of the verbs were examined in four representative CFL dictionaries. It was found that the dictionaries under investigation had the following major problems: incomplete macrostructure, missing causative sense, and lack of grammatical and usage information. On the basis of these findings, this paper proposed the methods to represent causative psych verbs in the CFL dictionaries with model entries. The proposed methods and models are applicable to the practice of dictionary making, and thus they are particularly significant both to lexicography and teaching and learning Chinese as a Foreign Language.
\end{abstract}

Keywords-Causative psych Verb; the learner's Chinese Dictionary; Chinese as a Foreign Language; Semantics; Syntax; Lexicography

\section{INTRODUCTION}

With the development of China's society and economy, more and more foreigners begin to learn Mandarin. It was reported that the number of people learning Chinese as a foreign language (CFL) in the world has reached 40 million by the year 2017 [1]. The Chinese fever has promoted the compilation and publication of the dictionaries for learners of Chinese as a Foreign Language. Since the 1990s, a number of these dictionaries have been published successively. However, existing research indicates that they were rarely used by their target users [2-4]. There could be multiple reasons for this phenomenon. One of the most important ones might be the problem of homogeneity. The CFL dictionaries tend to be almost identical to the general Chinese dictionaries in forms and structures. The former may copy or simplify the definitions of the latter without giving due attention to the special needs of the CFL learners.

Psych verbs indicate a change in psychological state, such as shock, satisfy, or worry. They comprise three types: dynamic, stative and causative. Owing to their distinctive semantic and syntactic features, psych verbs have recently aroused growing interest of scholars. They discussed the definitions, classification and nature of the psych verbs.

This work was supported in part by the Department of Education of Guangdong Province under Grant 2017WTSCX32: A Study on the Definitions of Chinese-English Dictionaries for CFL Learners, and Guangdong Planning Office of Philosophy and Social Science under Grant GD14XWW20: A Corpus-based Study on China English.
Previous literature focused on the dynamic and stative psych verbs themselves from the perspectives of cognitive semantics, psychological linguistics and language acquisition [5-10]. Less research was done on causative psych verbs [11-14]. Besides, no literature has been found to approach causative psych verbs from the angle of lexicography. Therefore, this present study will explore the semantic and syntactic features of causative psych verbs and their representation in CFL dictionaries.

\section{SEMANTIC AND Syntactic FEATURES OF CAUSATIVE PSYCH VERBS}

A causative psych verb shows that someone or something (X) causes other people (Y) to be in a psychological state or undergo some kind of psychological change. In other words, the agent $(\mathrm{X})$ is the cause of making the experiencer $(\mathrm{Y})$ to be in a state. The experiencer perceives the outside world and gains information in a passive way. By the degree of causative explicitness, causative psych verbs can be divided into two types: explicit or implicit [15]. While Explicit causative psych verbs have causative meaning themselves, such as jidong (excite), xia (frighten), gandong (touch), etc., implicit causative psych verbs do not have causative meaning themselves but function as a causative verb in some cases, such as ai (love), hen (hate), pa (fear), etc. Therefore, the verb's original meaning is different from its meaning as a causative verb.

Causative psych verbs involve external things, causative force, people (causative object), brain organs, psychological state or change. They have common semantic features: [external thing] (agent) + [causative force] + [people] (causative object) + [brain organ] + [psychological state/change (causative result). Based on the semantic and syntactic characteristics of Chinese causative psych verbs, they can be categorized into 4 major groups.

\section{A. Experiencer as Object}

As a universal language phenomenon, Chinese and English share the basic semantic and syntactic structure as shown below:

$$
\mathrm{S} \text { (agent) }+\mathrm{V}(\mathrm{p})+\mathrm{O} \text { (experiencer) }
$$

In pattern $1, \mathrm{~S}$ stands for subject, $\mathrm{V}(\mathrm{p})$ for psych verb, and $\mathrm{O}$ for object. Most explicit causative psych verbs fall into this group, such as konghe (threaten), anwei (comfort), dadong (touch), manzu (satisfy), fanrao (bother), xiahu (frighten), mi (enchant), chou (worry), etc. 


\section{Ex. 1 Wo xiahu ta. (I frighten her.)}

Ex. 2 Wo yizhi shitu anwei Yaoming. (I tried to comfort Yaoming all the time.)

In Ex. 1 and Ex. 2, the agents (wo) cause the experiencers (ta and Yaoming) to feel scared (Ex.1) or comfortable (Ex.2). As Chinese and English share the same sentence pattern, CFL learners may have a positive transfer from their native language.

\section{B. Pivotal Structure}

In English there are such affixed verbs as frighten, horrify, terrify, which make it possible for English speakers to make such an utterance like "We don't want to frighten them". Chinese is not a language which is rich in affixed words. Therefore, in order to express the same meaning in Chinese, we have to use a pivotal structure like "women bu xiang shi/ling/rang tamen haipa (we don't want to make them frightened)". The syntactic function and arguments for these affixed verbs are not matched in Chinese and English. In Chinese, "haipa" is a verb which requires the experiencer as a subject, not an object like that in English. Therefore, the structure in Chinese is shown below:

$\mathrm{N} 1$ (agent) + shi/ling/rang (make/cause/let) + N2 (experiencer/agent) $+\mathrm{V}(\mathrm{p})$

In pattern 2, N2, indicating the second noun in the sentence, is the object of the verb shi (make), ling (cause), or rang (let), and at the same time the subject of the $V(p)$. This is called a pivotal structure in Chinese in which the first verb must be linked with two obligatory arguments, one of them precedes it and the other follows it. As a result, CFL learners may make an ungrammatical sentence like "*women bu xiang haipa tamen (we don't want to frighten people)" due to linguistic transfer.

The following verbs fall into this group: haipa (frighten), pa (frighten), ai (love), taoyan (dislike), hen (hate), хіи (disgrace), keling (pity), danxin (worry), manyi (satisfy), shiwang (disappoint), etc. For these verbs, Chinese and English differ from each other in the semantic parameters. That is to say, English verbs require an experiencer as object, but Chinese verbs require a pivotal structure.

Ex. $3 *$ Ta de jiankang danxin women. (His health worried us.)

Ex. 4 Ta de jiankang rang women danxin. (His health made us worried.)

In Ex. 3, the English sentence is correct, but the Chinese one is not. In Ex. 4, the pivotal structure is used, in which the second noun "women" is the object of the causative verb "rang" and the subject of the verb "danxin".

\section{Auxiliary Bonded Structure}

In Chinese, auxiliaries can be used to indicate the tense and aspect of the action. They can also be used to form a causative structure as indicated in pattern 3 .

$$
\mathrm{S} \text { (agent) }+\mathrm{V}(\mathrm{p})+\text { zhuo/le/guo }+\mathrm{O} \text { (experiencer) }
$$

In pattern 3 , the causative psych verb is followed by an auxiliary "zhuo", "le", or "guo" which is an indicator of the tense, and can make the causative sentence grammatical. If none of the auxiliaries is used, the sentence is not acceptable.

Ex. 5 *Tade gushi gandong women. (Her story touched us.)

For Ex. 5, pattern 1 can be used directly in English, but in Chinese, either pattern 2 or pattern 3 should be used. Otherwise, it is not acceptable in Chinese.

Ex. 6 Tade gushi gandong le women. (Her story touched us.)

Ex. 7 Zhege wenti yizhi kunrao zhuo women. (The problem has always bothered us.)

In Ex. 6 and Ex. 7, the auxiliaries "le" or "zhuo" are added after the verb to show the past tense or the present perfect tense, which make the sentence grammatical. These verbs include dadong (touch), zhenjing (shock), zhenfen (cheer up), xingfen (excite), mihuo (puzzle), etc. In English, the past tense or perfect tense is used at the above cases. The structural difference between Chinese and English may lead to negative transfer. A CFL learner could make a sentence like "*tade gushi gandong women (Her story touched us)" according to the English structure.

\section{Causative/Stative Alteration}

Apart from these structural differences, some causative psych verbs in English can undergo a process of causative and stative alteration, in which the original causative use of the verb is changed into the stative use.

\section{Ex. 8a What others think doesn't worry Nate.}

\section{Ex. 8b Nate doesn't worry about what others think}

In the above examples, the verb's arguments changed their positions with each other, in which the object in Ex. 8a became the subject in Ex. 8b, and the verb is followed by a preposition in Ex. 8b. That is to say, the experiencer became the subject of the sentence, and thus the verb described a state. Although Ex. 8a and Ex. 8b have almost the same meaning, the use of the verb in Ex. 8b is no longer causative, but stative. In Chinese, the causative and stative alteration is realized by a pivotal structure instead of adding a preposition as shown in Ex. 9.

Ex. 9 Zhege wenti ling women fannao. (The problem made us worried./We worried about the problem.)

These verbs include yuyue (delight), mihuo (puzzle), exin (sadden), danxin (worry), gaoxing (delight), danyou (bother), beishang (grieve), etc.

\section{TREATMENT OF CAUSATIVE PSyCH VerbS IN EXISTING LEARNER'S CHINESE DICTIONARIES}

In this study, four learner's Chinese dictionaries were chosen to examine the treatment of causative psych verbs in these dictionaries. They are Shangwuguan Xue Hanyu Cidian (The Commercial Press's Learner's Dictionary of Contemporary Chinese) (SXHC)[16], Dangdai Hanyu Xuexi Cidian (Learner's Dictionary of Contemporary Chinese) (DHXC) [17], Hanyu Changyongzi Xiangjie Zidian (A Dictionary of Commonly Used Chinese Characters) (HCXZ) [18], and Xiandai Hanyu Babai Ci (Eight Hundred Characters of Contemporary Chinese) (XHBC) [19] as they are the most 
popular CFL learner's dictionaries available in the Chinese market. Ten causative psych verbs were selected randomly: anwei (comfort), dadong (touch), xiahu (frighten), manyi (satisfy), shiwang (disappoint), zhenjing (shock), zhenfen (cheer up), xingfen (excite), mihuo (puzzle), and danxin (worry). Each of the verbs was checked in the four dictionaries against the following items: headword status (whether it was included as a headword), causative sense (whether a causative sense was listed), definition (whether its definition showed causative meaning), grammatical information (whether its grammatical information was given), example (whether an illustrative example was used to show causative use), and note (whether a note was devised to help dictionary users to use the word). The results were shown in TABLE I.

TABLE I. TREATMENT OF CAUSATIVE PSYCH VERBS IN CHINESE DICTIONARIES

\begin{tabular}{|l|c|c|c|c|}
\hline \multicolumn{1}{|c|}{ Treatment } & SXHC & DHXC & HCXZ & XHBC \\
\hline Headword status & 9 & 0 & 0 & 0 \\
\hline Causative sense & 2 & 0 & 0 & 0 \\
\hline Definition & 2 & 0 & 0 & 0 \\
\hline $\begin{array}{l}\text { Grammatical } \\
\text { information }\end{array}$ & 0 & 0 & 0 & 0 \\
\hline Example & 3 & 1 & 0 & 0 \\
\hline Note & 0 & 0 & 0 & 0 \\
\hline
\end{tabular}

From TABLE I, it can be found that SXHC showed the best performance in representing the ten verbs. Except the verb "mihuo (puzzle)", the other nine verbs were included in the dictionary as a headword. The two verbs "dadong (touch)" and "zhenjing (shock)" had causative senses. The other dictionaries did not do well in treating these verbs. By examining the existing dictionaries, the following major problems were identified.

\section{1) Incomplete macrostructure}

Except SXHC, the other three dictionaries did not include the ten verbs as headwords although DHXC included "manyi" and "shiwang" as an adjective. In fact, some of the ten verbs belong to level A (e.g. daxin) and B (e.g. anwei, shiwang), which should not be missing in the macrostructure of a learner's dictionary.

\section{2) Missing causative sense}

Only two headwords included in SXHC had a causative sense. The causative senses of other verbs were not listed in the four dictionaries, which are an important part of the words' meanings.

3) Insufficient grammatical and usage information

SXHC provided some grammatical and collocational information in the micro-structure. For examples, it defined the two verbs as below:

Ex. 10 dadong: yanxing shi ren gandong (words and action make people moved)

Ex. 11 zhenjing: (mei xiangdao de zhongda shiqing) (some unexpected important events) rang ren chijing (make people shocked)
In Ex. 10, a full sentence definition was used to show that the verb "dadong" usually co-occurs with "words and action". In Ex. 11, a gloss was used to give collocates of the verb. They are very helpful to Chinese learners. However, only these two entries provided this information. The other entries lack of necessary grammatical and usage information. The causative psych verbs have some special semantic and syntactic features, such as the pivotal structure, the auxiliary bonded structure and causative/stative alteration, etc. All the four dictionaries failed to represent them.

\section{Defining CAusative Psych Verbs IN LEARNER'S DICTIONARIES}

By defining, it means, in this paper, all the measures and devices used to explain the meanings and usages of the headword. A learner's dictionary should give full consideration to its users' learning habits, learning styles and learning strategies, pinpoint the source of their problems and provide possible solutions in the dictionary to promote their language acquisition.

The most prominent semantic feature of a causative psych verb is its causative meaning, which is the key conceptual schema to be described in the dictionary. The focus of the description should be on the various linguistic rules governing the use of the causative verbs through various means such as examples, glosses, notes, collocation columns, error warnings, synonym discriminations, and cross references, etc. in order to provide the headword's grammatical, pragmatic, register, and style information.

Ex. 12 danxin dongci (verb) (1) fangxin buxia (worry about): wo danxin tade xuexi.(I worried about his study.) (2) [shi/ling/rang ren danxin] (ren/shi) (sb/sth) shi ren fangxin buxia (worry): tade anquan rang women danxin. (Her safety worried us.)

cuowu tishi (Error Warnings):buyao shuo "tade jiankang danxin women." ying shuo "tade jiankang rang women danxin." (Do not say "tade jiankang danxin women.", but say "tade jiankang rang women danxin." )

Ex. 13. gandong dongci (verb) (1) jidong (excite): wo tingwan hen gandong.(I was very excited after hearing this.) (2)[gandong zhuo/le/guo ren] [shi/ling/rang ren gandong] (yanxing) (words or action) shi ren jidong (make people excited): tongxuemen de bangzhu gandong le ta. (His classmates' help touched him.)

cuowu tishi (Error Warnings):buyao shuo "Wang Linxiang de zhencheng gandong tamen" ying shuo "Wang Lixiang de zhenzheng gandong le tamen.", huozhe " Wang Lixiang de zhenzheng ling tamen gandong." (Do not say "Wang Linxiang de zhencheng gandong tamen", but say "Wang Lixiang de zhenzheng gandong le tamen." or "Wang Lixiang de zhenzheng ling tamen gandong." )

In Ex. 12 and Ex. 13, the causative meanings of headwords were listed as a separate sense. The causative senses were defined with the causative marker "shi"(make) and the patient "ren" (people), from which the dictionary users can tell the difference between the general sense and causative sense, and can see that the object of the causative use is people. 
The syntactic features of the causative psych verbs in Chinese and English can be attributed to the cognitive mechanism shared by human beings. For example, in English some affixed verbs such as frighten, horrify, etc. can be used to express the causative meaning, and in Chinese a pivotal structure can be used to fulfill the same semantic and grammatical function. In Ex. 12 and Ex. 13, the sentence patterns were given in glosses, such as [gandong zhuo/le/guo ren] to show the dictionary users how to make grammatical sentences with these causative verbs. Moreover, collocational information was given in the model entries through various means, such as glosses, definitions and examples. By doing so, not only the co-occurrence of words, but also the cognitive mechanism behind their co-occurrence is explained. Last, but not the least important, an error warning was set up to advise CFL learners against negative transfer of their mother tongue.

\section{CONCLUSION}

This paper takes the causative psych verbs as an example to discuss their representation in the CFL dictionaries from user's perspective. A CFL learner's dictionary aims to help learners learn Chinese. The English learner's dictionary has shifted from a traditional consultation tool to an aid to learning a foreign language. However, the Chinese learner's dictionary still focuses on definitions in the traditional way, lacking necessary learning characteristics. Therefore, the most important thing in the compilation of the CFL dictionary is to change the current compilation concept. Dictionary writers should consider the cognitive characteristics of CFL learners and the needs of their dictionary consultation, and provide multi-dimensional information that is conducive to CFL learners' acquisition of Chinese.

The study extends research on causative psych verbs, and its findings can be applied to the practice of dictionary writing. Moreover, the semantic and syntactic features of causative psych verb identified in the study are meaningful to teaching Chinese as a foreign language.

\section{REFERENCES}

[1] R. Chai, and Z. Wang, "The number of people learning Chinese in the world has exceeded 100 million", http://news.cctv.com/2017/10/28/ARTIUuIlgFPLIWKv25vXJ6Lm1710 28.shtml, 2017. (In Chinese)

[2] Q. Huang, K. Huang, and T. Chen, The Chinese Broken Marks Dictionary. Beijing: The Commercial Press, 2011. (In Chinese)

[3] L. Xia, "An investigation into the publication of CFL dictionaries from user perspective”, Publication Science, 17(1), pp. 65-69, 2009. (In Chinese)

[4] Y. Zhang, “A contrastive study on the learner's Chinese dictionaries and the general Chinese dictionaries”, Academic Research, 9, pp. 151-156, 2010. (In Chinese)

[5] C. H. Cheung, and R. K. Larson, "Chinese psych verbs and covert clausal complementation”, Chicago Workshop on Chinese Linguistics, At Chicago, IL, United States, pp. 2-14, 2006.

[6] C. H. Cheung, and R. K. Larson, "Psych verbs in English and Mandarin", Natural Language \& Linguistic Theory, 33(1), pp. 127-189, 2015.

[7] W. Ding, “A study on psych verbs in contemporary Chinese”, M.A Dissertation of Shanghai Normal University, 2008. (In Chinese)

[8] Q. Qi, "Syntactic structures of psych verbs in modern Chinese", Philological Journal, 9, pp.15-17, 2015. (In Chinese)

[9] J. Zhang, "Chinese psych verbs and their syntactic constructions, Tangdu Journal, 67(117), pp. 112-115, 2001. (In Chinese)

[10] Y. Zhou, and J. Shao, “Chinese psych verbs and their sentence patterns”, Philological Research, 8, pp. 32-36, 48, 1993. (In Chinese)

[11] H. Chang, "A study of the acquisition of Chinese causative constructions by native English speakers”, International Chinese Teaching, 1(25), pp. 129-140, 2011. (In Chinese)

[12] W. Wang, and R. Xu, "The morphological categories and syntactic structures of pysch causative verbs in English and Chinese”. Journal of Foreign Languages, 4(158), pp. 22-29, 2005. (In Chinese)

[13] Y. Zhang, "An analysis of the syntactic and semantic features of causative psych verbs”. Philological Journal, 12, pp. 39-41, 2013. (In Chinese)

[14] J. Zhang, “A contrastive study on causative psych verbs in English and Chinese”. Foreign Language Research, 3(69), pp. 46-50, 2001. (In Chinese)

[15] Y. Wen, “A Study on Modern Chinese Psychological Verbs”, Ph. D. Dissertation of Beijing Language and Culture University, 2007. (In Chinese)

[16] J. Lu, and W. Lü, The Commercial Press's Learner's Dictionary of Contemporary Chinese. Beijing: The Commercial Press, 2006. (In Chinese)

[17] Y. Xu, Learner's Dictionary of Contemporary Chinese. Beijing: Beijing Language and Culture University Press, 2005. (In Chinese)

[18] H. Ji, and R. Feng, A Dictionary of Commonly Used Chinese Characters. Wuhan: Hubei Education Press, 2002. (In Chinese)

[19] S. Lü, Eight Hundred Characters of Contemporary Chinese. Beijing: The Commercial Press, 1999. (In Chinese) 